\title{
Effect of Preexisting Cracks on Lap Splice Strength of Reinforcing Bars
}

\author{
by Jiqiu Yuan, Matthew O'Reilly, Adolfo Matamoros, and David Darwin
}

The effect of preexisting subsurface cracks on the strength of lap splices was investigated. Ten full-scale beams with No. 11 (No. 36) bars and lap splice lengths of 33, 79, and $120 \mathrm{in}$. (838, 2007, and $3048 \mathrm{~mm}$ ) were tested. The beams had mitigating features that prevented catastrophic failure upon propagation of the preexisting cracks, such as staggered splices and the presence of some reinforcement crossing the plane of the cracks. The effect of preexisting cracks on the bar stress at failure was found to be most severe for the shortest splices and not significant for the two other splice lengths evaluated. The effect was found to be dependent on the amount of reinforcement crossing the plane of the cracks. Splice strength was unaffected in beams with the largest amount of reinforcement, and reduced on the order of $50 \%$ in beams without any reinforcement crossing the plane of the cracks.

Keywords: bond strength; cold joint; crack width; cracks; cyclic loading; lap splice; preexisting cracks.

\section{INTRODUCTION}

This paper presents the findings of a study investigating the effect of preexisting cracks oriented in the plane of the reinforcing steel on the strength of lap splices. Cracks of this type are of interest because they have the same location and configuration as cracks that form when bars undergo slip prior to the failure of lap splices (Untrauer 1965; Tepfers 1973; Orangun et al. 1977; Eligehausen 1979; Darwin et al. 1996, 2016; Zuo and Darwin 2000; ACI Committee 408 [2003]). As a result, these cracks raise the concern that their presence will lead to lower splice strength. Recently, preexisting cracks in the plane of the reinforcing steel were found in the shield building of a nuclear power station (NRC 2013). Cracks were observed in the field with a width of 10 mils $(0.25 \mathrm{~mm})$ or less in a containment structure with No. 11 (No. 36) reinforcing bars. The No. 11 (No. 36) bars in this particular structure had staggered splices with lengths of 79 or $120 \mathrm{in.} \mathrm{(2007} \mathrm{or} 3048 \mathrm{~mm}$ ). The goal of the study was to evaluate the effect of preexisting cracks with a minimum width of 10 mils $(0.25 \mathrm{~mm})$ on splice strength. This crack width was chosen to be representative of crack widths observed in the field. The specimens tested contained No. 11 (No. 36) reinforcing bars with splice lengths of 33, 79, and 120 in. $(838,2007$, and $3048 \mathrm{~mm})$.

\section{RESEARCH SIGNIFICANCE}

The effect of preexisting cracks on lap splice strength is of serious concern to engineers because development and splice failures are associated with splitting cracks along the plane of the reinforcement. Experimental data on the strength of splices in members with preexisting cracks presented in this paper will be helpful to engineers responsible for evaluating structures with similar types of damage in the future.

\section{EXPERIMENTAL PROCEDURE Specimen properties}

A total of ten beams were tested with cross sectional dimensions of $18 \times 24 \mathrm{in}$. $(457 \times 610 \mathrm{~mm})$ and a top clear cover of 3 in. $(75 \mathrm{~mm})$. Specimen configurations and properties are shown in Fig. 1 and summarized in Table 1. Two groups of specimens were used in the study, each with a different configuration.

Group 1 consisted of four beams with three No. 11 (No. 36) bars as main flexural reinforcement, in which only the center bar was spliced to simulate the effect of staggering splices (Fig. 1(a)). Beams in this group had a nominal side clear cover of 2.3 in. $(58 \mathrm{~mm})$, measured from the surface of the concrete to the outside of the continuous bars. These four specimens were cast with cold joints at the midheight of the reinforcement to simulate the presence of preexisting cracks. Beams 1 and 2 (refer to Table 1) had an $8 \mathrm{ft}(2438 \mathrm{~mm})$ long cold joint, centered on the beam, and contained eight No. 3 (No. 10) bar side hoops crossing the plane of the cold joint on each side of the splice region, outside of the continuous bars. The hoops were placed with the intent of simulating the upper bound on restraint that could be provided by adjacent concrete in the vicinity of a preexisting crack. The No. 3 (No. 10) bar side hoops had dimensions of $6 \mathrm{x}$ 21 in. $(152 \times 533 \mathrm{~mm})$ and were spaced at 6 in. $(152 \mathrm{~mm})$ between adjacent hoops. Beams 3 and 4 had a $20 \mathrm{ft}$ (6096 $\mathrm{mm}$ ) long cold joint and contained no side hoops to simulate minimum restraint from adjacent concrete in the vicinity of a preexisting crack.

Group 2 consisted of six beams with two spliced No. 11 (No. 36) bars as main flexural reinforcement (Fig. 1(b)). The beams in this group had a nominal side concrete clear cover of 3 in. $(76 \mathrm{~mm}$ ) measured to the outermost No. 11 (No. 36) bar. One of the beams (Beam 5) was cast monolithically, while the remaining beams (Beams 6 to 10) were cast with a cold joint in the plane of reinforcing steel. The specimens in Group 2 with cold joints had one No. 3 (No. 10) bar side hoop (12 x 21 in. [305 x $533 \mathrm{~mm}])$ crossing the plane of the cold joint on each side of the beam, centered on the splices

ACI Structural Journal, V. 113, No. 4, July-August 2016.

MS No. S-2015-086.R3, doi: 10.14359/51688753, received August 7, 2015, and reviewed under Institute publication policies. Copyright (C) 2016, American Concrete Institute. All rights reserved, including the making of copies unless permission is obtained from the copyright proprietors. Pertinent discussion including author's closure, if any, will be published ten months from this journal's date if the discussion is received within four months of the paper's print publication. 


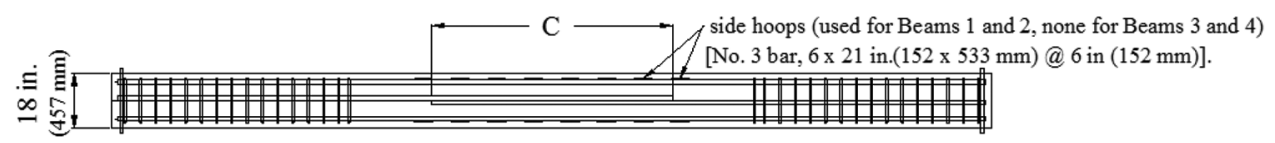

Plan

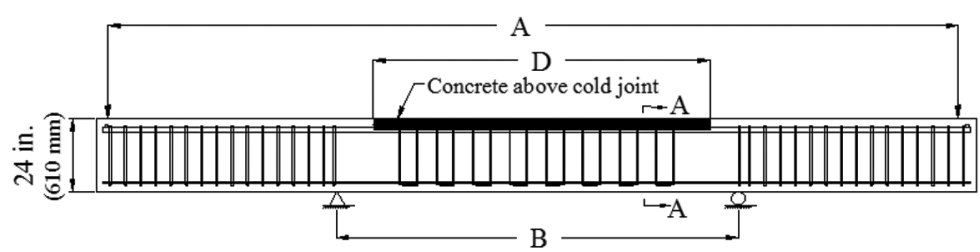

Elevation

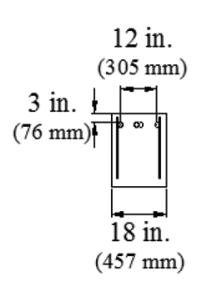

A-A

(a)
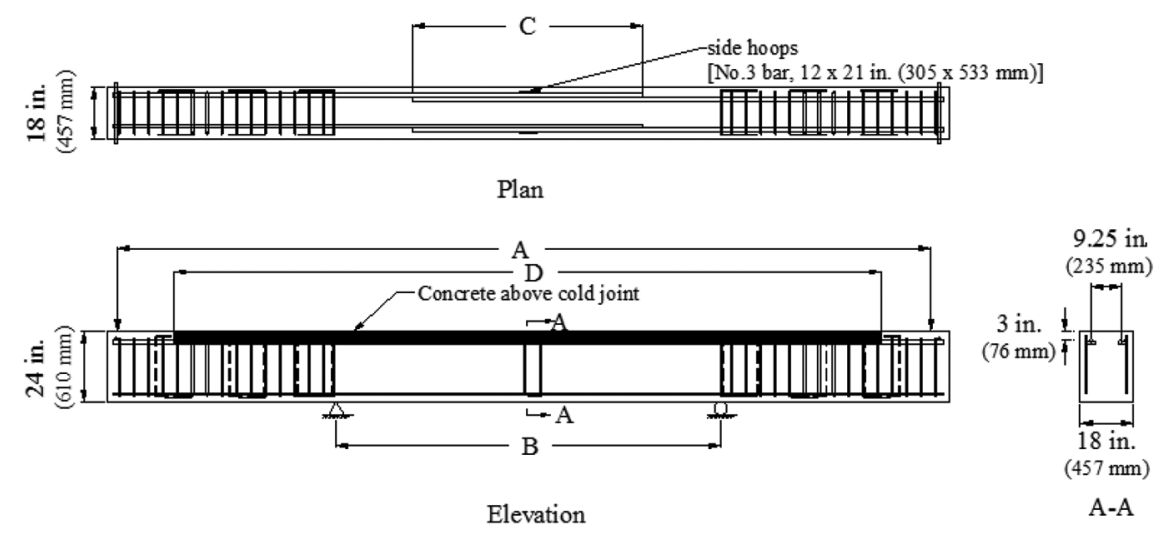

(b)

Fig. 1-Beam properties and dimensions: (a) Group 1-one spliced bar at center and two continuous bars outside (Beams 1 through 4); and (b) Group 2-two spliced bars (Beams 5 through 10).

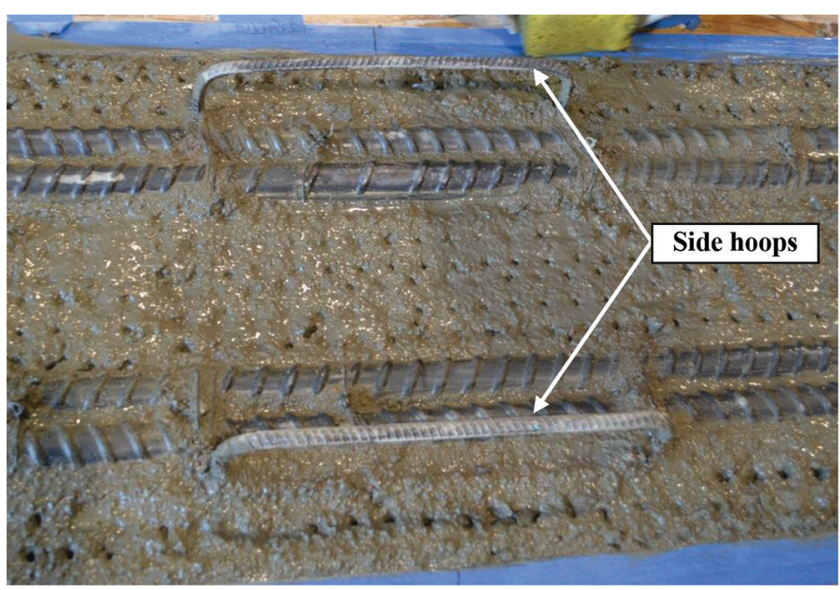

Fig. 2-Side hoops crossing plane of cold joint in Beams 5 through 10, outside spliced bars, at center of specimen.

(Fig. 2). Beams 5 through 7 had a splice length of 79 in. $(2007 \mathrm{~mm})$. Beams 6 and 7 had a $20 \mathrm{ft}(6096 \mathrm{~mm})$ long cold joint. Beams 8 through 10 had a splice length of 120 in. $(3048 \mathrm{~mm})$ and a $23 \mathrm{ft}(7010 \mathrm{~mm})$ long cold joint.

As shown in Fig. 1, the beams were subjected to four-point loading to provide a constant moment in the splice region. The spacing of the supports was chosen so that the distance from either end of the splice to the central pin-and-roller supports was equal to or greater than the effective depth of the beam. Outside the pin-and-roller supports, the beams were subjected to constant shear. Grade 60 (420) closed No. 3 (No. 10) hoops were placed in the constant shear region of all ten beams spaced at 5 in. $(127 \mathrm{~mm})$ on center (Fig. 3(a)). Two Grade 60 (420) No. 3 (No. 10) longitudinal bars were placed as the bottom layer of reinforcement in all beams to facilitate the placement of transverse reinforcement in the constant shear region.

\section{Simulation of preexisting cracks}

A cold joint at the midheight of the reinforcement was introduced to ensure that a longitudinal crack would develop in the plane of the reinforcing steel. The cold joints encompassed the entire length of the splices and extended outside of the splice region. The lengths of the cold joint and splice for each specimen are presented in Table 1 .

Specimens with cold joints were cast using two placements. In the first placement, concrete was cast up to the center of the top layer of reinforcement. Beams 1 and 2 were cast with two layers of painter's tape within the cold joint to serve as crack initiators. The painter's tape was placed adjacent to the spliced bars (Fig. 3(a)). The rest of the beams were cast without painter's tape in the cold joint. To simulate the roughness of a natural crack in Beams 3 through 10 , the surface of the cold joint was treated by introducing indentations while the concrete remained plastic (Fig. 3(b)). The exposed reinforcing steel was cleaned using sponges 
Table 1-Specimen dimensions and properties

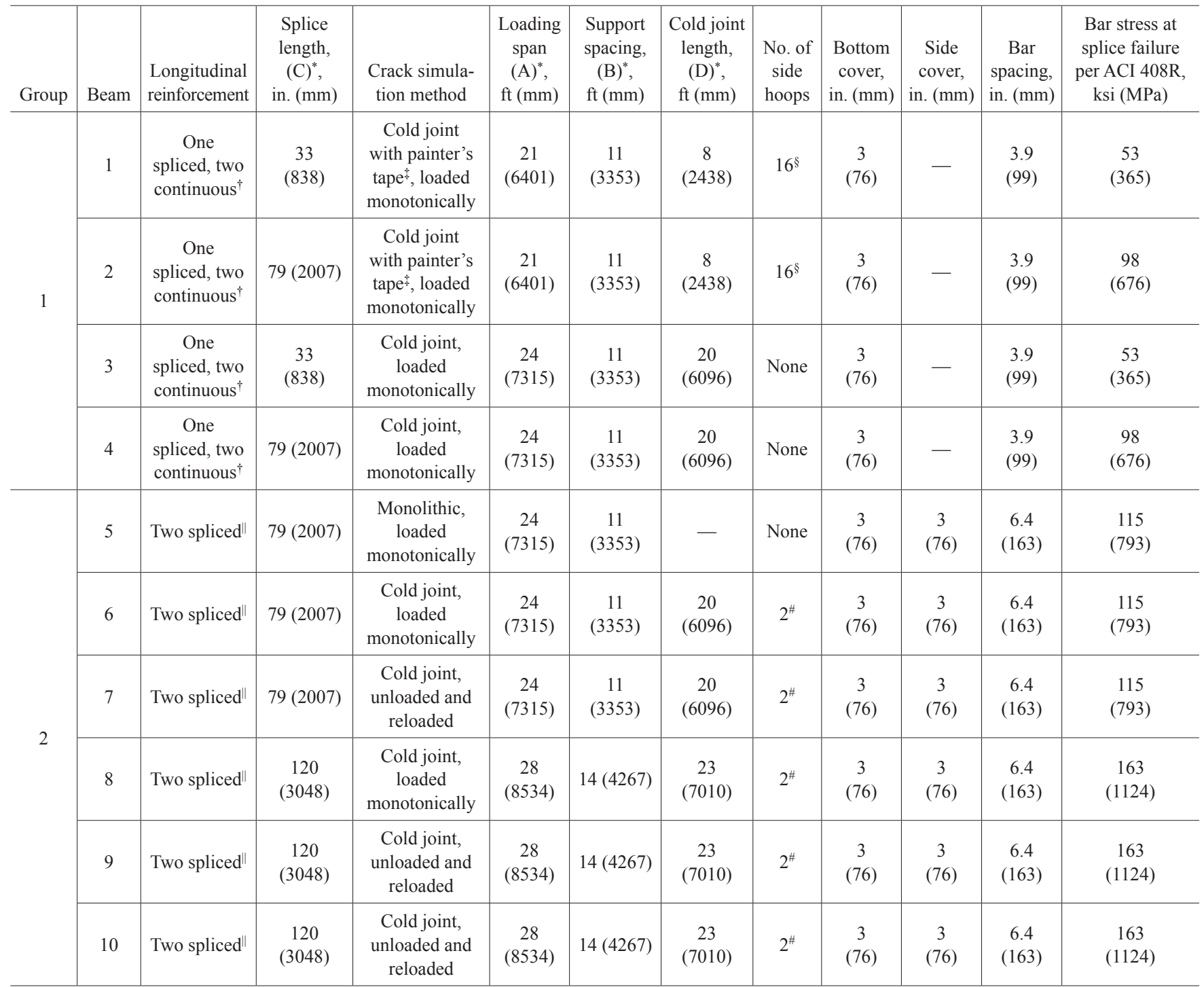

${ }^{*}$ Refer to Fig. 1.

'Refer to Fig. 1(a).

${ }^{\ddagger}$ Refer to Fig. 3(b).

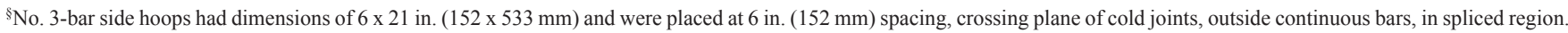
"Refer to Fig. 1(b).

\#No. 3 bar side hoops had dimensions of $12 \times 21$ in. $(305 \times 533 \mathrm{~mm})$, crossing plane of cold joint, outside spliced bars, only at center of specimen.

to allow adequate bond between the exposed bars and the concrete cast during the second placement. Specimens were moist-cured until the remainder of the concrete was placed, no later than 26 hours after the original placement. Concrete for the second placement had the same mixture proportions and was supplied by the same ready mix plant as the first. Before the second placement, the concrete surface was cleaned using compressed air to remove debris and loose concrete, and maintained in a wet condition until the second placement started. After casting, the specimens were moistcured until the compressive strength of the concrete from the first placement exceeded $3500 \mathrm{psi}(24.1 \mathrm{MPa})$.

\section{Reinforcing steel}

The flexural reinforcement in all specimens consisted of No. 11 (No. 36) bars. The No. 11 (No. 36) bars used in
Beams 1 and 2 had a yield stress of $71 \mathrm{ksi}(489 \mathrm{MPa})$ and tensile strength of $108 \mathrm{ksi}$ (745 MPa). The No. 11 (No. 36) bars in Beams 3 to 10 had a yield stress of $67 \mathrm{ksi}(462 \mathrm{MPa})$ and tensile strength of $105 \mathrm{ksi}(724 \mathrm{MPa})$. The mean deformation height and spacing of the No. 11 (No. 36) bars met the requirements of ASTM A615 and the relative rib area was within the typical range for conventional reinforcement in U.S. practice (between 0.060 and 0.085) (ACI 408R-03 and ACI 408.3R-09).

\section{Concrete materials}

Concrete used to fabricate the test specimens was supplied by a local ready mix plant. The concrete was non-airentrained with Type I/II portland cement and a water-cement ratio $(w / c)$ of 0.42 . All splice specimens were tested when the concrete below the cold joint reached a compressive 


\begin{tabular}{|c|c|c|c|c|c|c|c|c|c|c|c|c|}
\hline \multirow[b]{3}{*}{ Group } & \multirow[b]{3}{*}{ Beam } & \multirow{3}{*}{$\begin{array}{l}\text { Concrete } \\
\text { placement }\end{array}$} & \multirow{2}{*}{\multicolumn{4}{|c|}{$\begin{array}{l}\text { Measured compressive strength, } \\
\text { psi (MPa) }\end{array}$}} & \multicolumn{6}{|c|}{ Measured modulus of rupture, psi (MPa) } \\
\hline & & & & & & & \multicolumn{3}{|c|}{ Monolithic beams } & \multicolumn{3}{|c|}{ Beams with cold joints } \\
\hline & & & $1^{\dagger}$ & $2^{\dagger}$ & $3^{\dagger}$ & Average & $1^{\dagger}$ & $2^{\dagger}$ & Average & $\# 1^{\dagger}$ & $\# 2^{\dagger}$ & Average \\
\hline \multirow{4}{*}{1} & \multirow{2}{*}{1 and 2} & Below & $\begin{array}{c}5010 \\
(34.5)\end{array}$ & $\begin{array}{c}5230 \\
(36.1)\end{array}$ & $\begin{array}{r}5040 \\
(34.7)\end{array}$ & $\begin{array}{l}5090 \\
(35.1)\end{array}$ & NA & NA & NA & \multirow{2}{*}{ NA } & \multirow{2}{*}{ NA } & \multirow{2}{*}{ NA } \\
\hline & & Above & $\begin{array}{l}4970 \\
(34.3)\end{array}$ & $\begin{array}{c}5310 \\
(36.6)\end{array}$ & $\begin{array}{c}5170 \\
(35.6)\end{array}$ & $\begin{array}{l}5150 \\
(35.5)\end{array}$ & NA & NA & NA & & & \\
\hline & \multirow{2}{*}{3 and 4} & Below & $\begin{array}{l}3810 \\
(26.3)\end{array}$ & $\begin{array}{l}4400 \\
(30.3)\end{array}$ & $\begin{array}{c}5940 \\
(41.0)\end{array}$ & $\begin{array}{l}4720 \\
(32.5)\end{array}$ & $\begin{array}{c}515 \\
(3.56)\end{array}$ & $\begin{array}{c}575 \\
(3.96)\end{array}$ & $\begin{array}{c}545 \\
(3.76)\end{array}$ & \multirow{2}{*}{$\begin{array}{c}225 \\
(1.54)\end{array}$} & \multirow{2}{*}{$\begin{array}{l}\text { Broke prior to } \\
\text { testing }\end{array}$} & \multirow{2}{*}{$\begin{array}{c}225 \\
(1.54)\end{array}$} \\
\hline & & Above & $\begin{array}{l}4560 \\
(31.4)\end{array}$ & $\begin{array}{c}4790 \\
(33.0)\end{array}$ & $\begin{array}{c}4420 \\
(30.5)\end{array}$ & $\begin{array}{l}4590 \\
(31.6)\end{array}$ & $\begin{array}{c}545 \\
(3.75)\end{array}$ & $\begin{array}{c}605 \\
(4.16)\end{array}$ & $\begin{array}{c}575 \\
(3.96)\end{array}$ & & & \\
\hline \multirow{4}{*}{2} & \multirow{2}{*}{$5^{\ddagger}, 6$, and 7} & Below & $\begin{array}{c}5150 \\
(35.5)\end{array}$ & $\begin{array}{c}5620 \\
(38.7)\end{array}$ & $\begin{array}{l}5210 \\
(35.9)\end{array}$ & $\begin{array}{c}5330 \\
(36.7) \\
\end{array}$ & $\begin{array}{c}610 \\
(4.21)\end{array}$ & $\begin{array}{c}525 \\
(3.62)\end{array}$ & $\begin{array}{c}570 \\
(3.93)\end{array}$ & \multirow{2}{*}{$\begin{array}{c}95 \\
(0.65)\end{array}$} & \multirow{2}{*}{$\begin{array}{c}180 \\
(1.24)\end{array}$} & \multirow{2}{*}{$\begin{array}{c}140 \\
(0.97)\end{array}$} \\
\hline & & Above & $\begin{array}{l}4710 \\
(32.5)\end{array}$ & $\begin{array}{l}4460 \\
(30.7)\end{array}$ & $\begin{array}{l}3830 \\
(26.4)\end{array}$ & $\begin{array}{l}4330 \\
(29.9)\end{array}$ & NA & NA & NA & & & \\
\hline & \multirow{2}{*}{8,9 , and 10} & Below & $\begin{array}{c}5170 \\
(35.6)\end{array}$ & $\begin{array}{c}5130 \\
(35.4)\end{array}$ & $\begin{array}{l}5380 \\
(37.1)\end{array}$ & $\begin{array}{l}5230 \\
(36.1)\end{array}$ & $\begin{array}{c}675 \\
(4.65)\end{array}$ & $\begin{array}{c}525 \\
(3.62)\end{array}$ & $\begin{array}{c}600 \\
(4.14)\end{array}$ & \multirow{2}{*}{$\begin{array}{c}320 \\
(2.20)\end{array}$} & \multirow{2}{*}{$\begin{array}{c}230 \\
(1.57)\end{array}$} & \multirow{2}{*}{$\begin{array}{c}275 \\
(1.86)\end{array}$} \\
\hline & & Above & $\begin{array}{c}5380 \\
(37.1)\end{array}$ & $\begin{array}{c}5580 \\
(38.5)\end{array}$ & $\begin{array}{c}5510 \\
(38.0)\end{array}$ & $\begin{array}{c}5490 \\
(37.8)\end{array}$ & $\begin{array}{c}660 \\
(4.56)\end{array}$ & $\begin{array}{c}740 \\
(5.10)\end{array}$ & $\begin{array}{c}700 \\
(4.83)\end{array}$ & & & \\
\hline
\end{tabular}

* Concrete placed below and above the cold joint.

${ }^{\dagger}$ Specimen ID.

†eam 5 was cast monolithically without second placement.

Note: NA is not available.

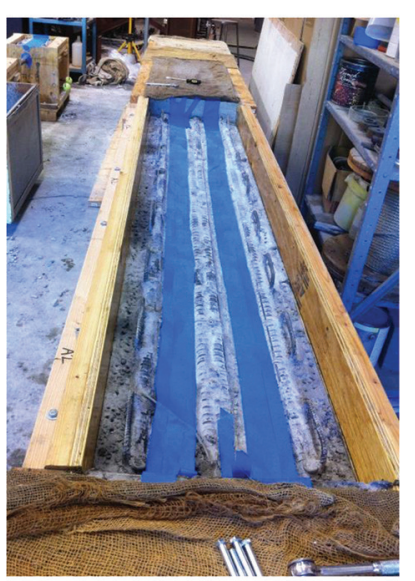

(a)

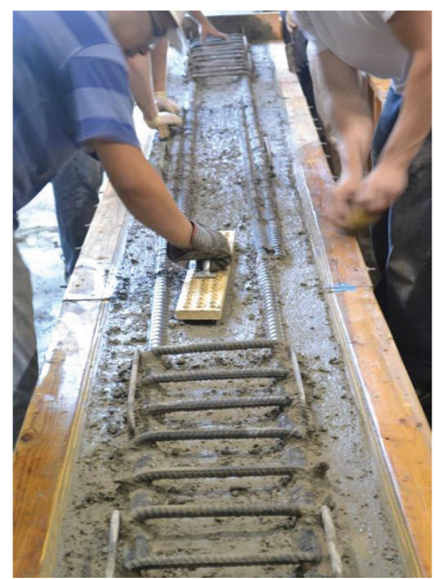

(b)

Fig. 3-(a) Painter's tape placed adjacent to spliced bars to serve as crack initiator for Beams 1 and 2; and (b) roughening of concrete surface at plane of cold joint; used for Beams 3 through 10.

strength of $5000 \pm 500 \mathrm{psi}(34.5 \pm 3.5 \mathrm{MPa})$. The measured compressive strength on the test date of each splice specimen is reported in Table 2.

The modulus of rupture of the concrete (an indicator of tensile strength) was measured in accordance with ASTM C78 (2010). Two flexure specimens were cast monolithically for each concrete placement, except for the concrete used in Beams 1 and 2 and the concrete placed above the cold joint in Beams 6 and 7. For beam-splice specimens with a cold joint, except for Beams 1 and 2, two extra flexure specimens were cast with a vertical cold joint at midspan. The flexure specimens with the cold joint were cast so that half of the

total length was filled with concrete from the mixture used below the cold joint in the splice specimens. After casting of the first segment, concrete on the surface of the vertical cold joint was roughed following the same procedure used for the beam-splice specimens. The second half of these flexure specimens was cast using concrete from the mixture used above the cold joint in the splice specimens. The flexure specimens were tested on the day the beam-splice specimens were tested; the results are reported in Table 2. Monolithic flexure specimens made with concrete mixtures used in Beams 3 and 4 had an average modulus of rupture of 560 psi (3.9 MPa), compared with $225 \mathrm{psi}(1.5 \mathrm{MPa})$ for the flexure beams cast with cold joints. For the concrete mixtures used in Beams 5 to 7, the monolithic and cold-joint flexure beams had average moduli of rupture of 570 and 140 psi (3.9 and 1.0 $\mathrm{MPa}$ ), respectively. For the concrete mixtures used in Beams 8 to 10 , the two average values of modulus of rupture were 650 and 270 psi (4.5 and 1.9 MPa), respectively. The test results show that the presence of the cold joint significantly reduced the tensile strength of the flexure beams. In most instances, the reduction was on the order of $60 \%$, and was as high as $75 \%$.

\section{Loading configuration and procedures}

The splice specimens were tested using a four-point loading configuration (Fig. 4). Loads were applied in the downward direction, with the main flexural reinforcement located at the top of the beam, to facilitate safe inspection of cracks in the area surrounding the splices. Forces were induced using hydraulic rams mounted under the laboratory floor and connected to threaded load rods. Steel girders spanning two load rods were used to transfer the load at each end 


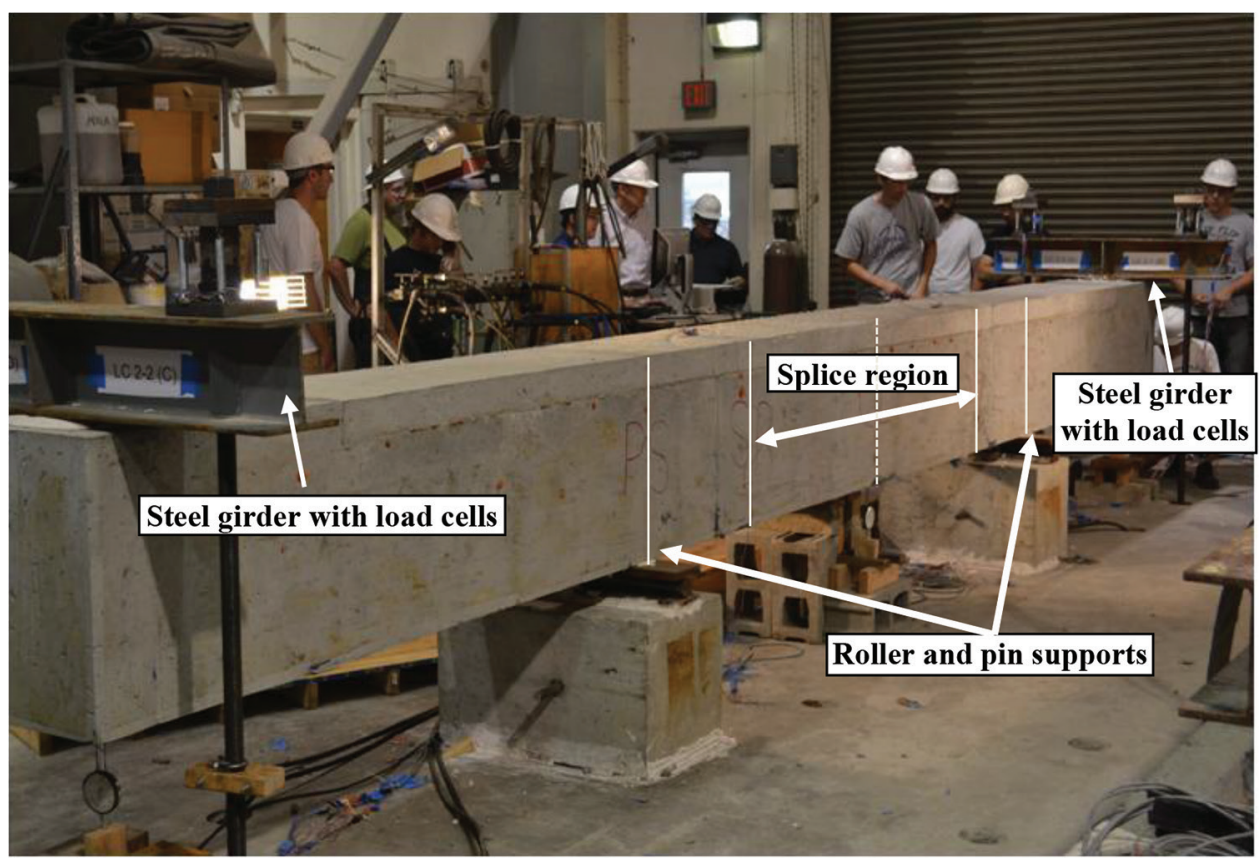

Fig. 4-Four-point loading configuration.

of the beams (Fig. 4). Hydraulic pressure was applied to the rams through a manifold while the force was recorded in load cells mounted on each of the load rods. The magnitude of the forces was closely monitored to ensure that equal-magnitude loads were applied on both ends of the beam. The splice region was located between the two supports, in the constant moment region of the beam. The beams were instrumented to measure the displacement at the ends and at midspan.

Two loading protocols were used, designated A and B. The two protocols had several characteristics in common. For both protocols, loading was stopped at predetermined intervals to allow inspection of the beam for cracks. The initial load increment was chosen to be smaller than one half of the calculated flexural cracking load to help ensure that all instruments and the hydraulic system were operating properly. After the initial increment, loading proceeded in increments of approximately 5 kip $(22 \mathrm{kN})$ at each end of the beam, with the exact load recorded at the end of each increment. After each load increment was completed, the beams were visually inspected, crack locations marked, and maximum crack widths recorded. For safety reasons, given the potential for a sudden failure, crack inspections were discontinued after two-thirds of the estimated failure load was exceeded.

Loading Protocol A, used for Beams 1 through 6 and Beam 8 , consisted of loading the beams monotonically to failure. Loading Protocol B, used for Beams 7, 9, and 10, involved two stages to ensure that a crack formed in the plane of the reinforcing steel prior to loading the beams to failure. During the first stage, beams were loaded monotonically until the measured width of the horizontal cracks at the cold joint exceeded 10 mils $(0.25 \mathrm{~mm})$. After the initial loading stage, specimens were unloaded and subsequently reloaded monotonically to failure.

\section{Procedure to calculate bar stress}

The average stress in the spliced bars was computed based on the calculated moment in the splice region using the moment curvature method in accordance with the procedure used to calculate bar stresses for ACI Committee 408 Database 10-2001 (2003). Moments were calculated using a two-dimensional analysis in which loads and reactions were assumed to act along the longitudinal centerline of the beam. The self-weight of the beam was included in the calculations based on average beam dimensions and an assumed concrete density of $150 \mathrm{lb} / \mathrm{ft}^{3}\left(23.6 \mathrm{kN} / \mathrm{m}^{3}\right)$. The stress in the reinforcement was computed using moment-curvature analysis, based on the concrete model proposed by Hognestad (1951).

\section{TEST RESULTS}

Load-deflection curves are presented for each beam (for example, Fig. 5 for Beams 1 through 4). The load shown in the figures corresponds to the total load applied to the beam; the deflection was calculated by adding the average of the two end point displacements and the displacement at the center of the beam. Points corresponding to changes in stiffness (changes in slope of the load-deflection diagram) and failure are shown in each figure. Loads and corresponding bar stresses at different stages of loading, including the load at which horizontal splitting cracks were first observed, are summarized in Table 3. The first reduction in stiffness in the load-deflection diagram correlated closely with the point at which flexural cracks were observed for the first time, in all instances, at a calculated bar stress based on cracked section properties of approximately $16 \mathrm{ksi}(110 \mathrm{MPa})$. Subsequent reductions in stiffness in the load-deflection diagram are attributed to either splice failure or yielding of the flexural reinforcement. A detailed description of measurements recorded during the tests is presented by Yuan et al. (2012). Key observations about the mode of failure of each beam are presented in the following. 

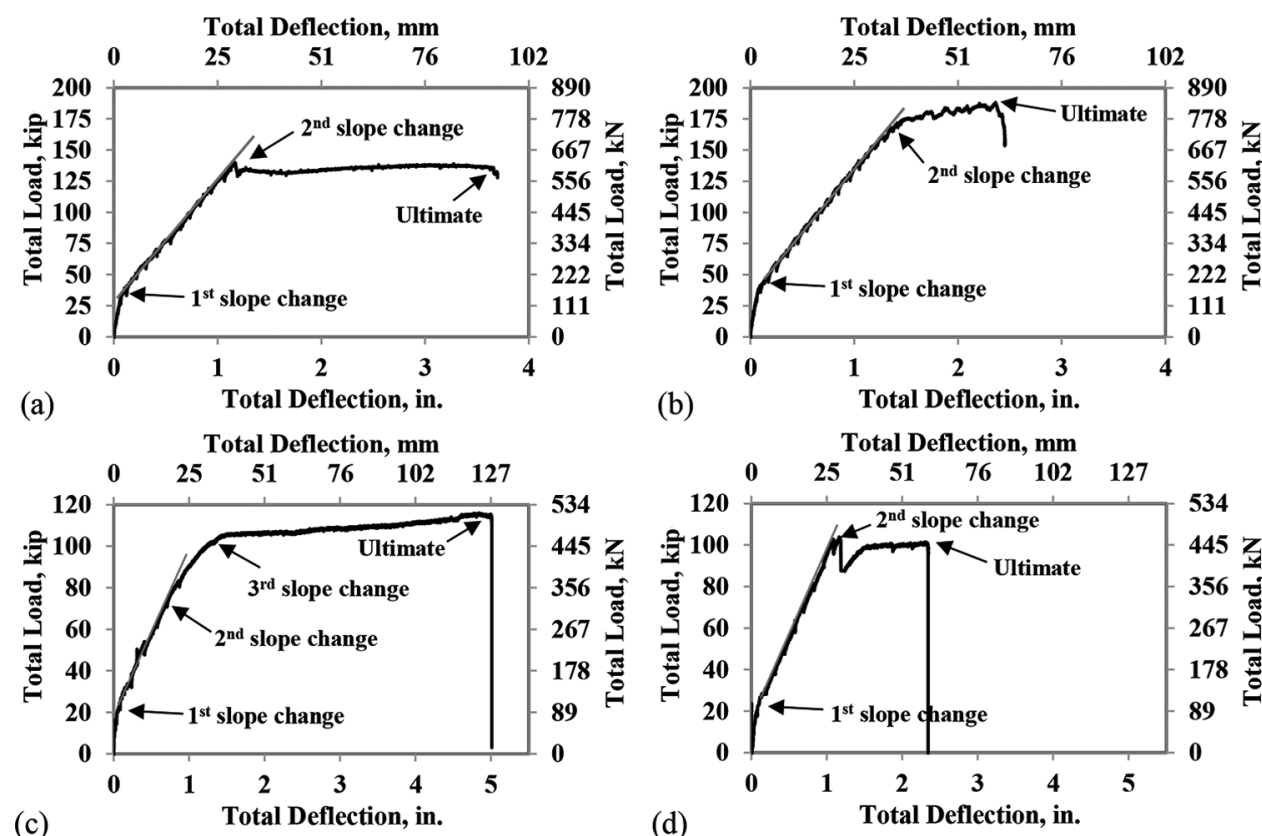

(b)

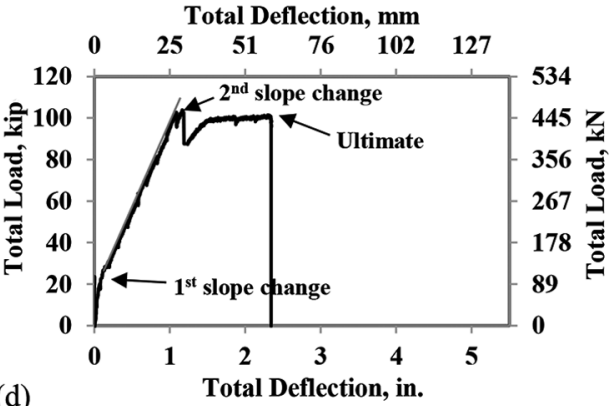

Fig. 5-Total load versus total deflection for: (a) Beam 1 (16 side hoops, $33 \mathrm{in.}[838 \mathrm{~mm}$ ] splice length); (b) Beam 2 (16 side hoops, $79 \mathrm{in.} \mathrm{[2007} \mathrm{mm]} \mathrm{splice} \mathrm{length);} \mathrm{(c)} \mathrm{Beam} 3$ (without side hoops, $33 \mathrm{in}$. [838 mm] splice length); and (d) Beam 4 (without side hoops, $79 \mathrm{in.}$ [2007 mm] splice length).

\section{Table 3-Bar stresses at different loading stages for beam-splice specimens}

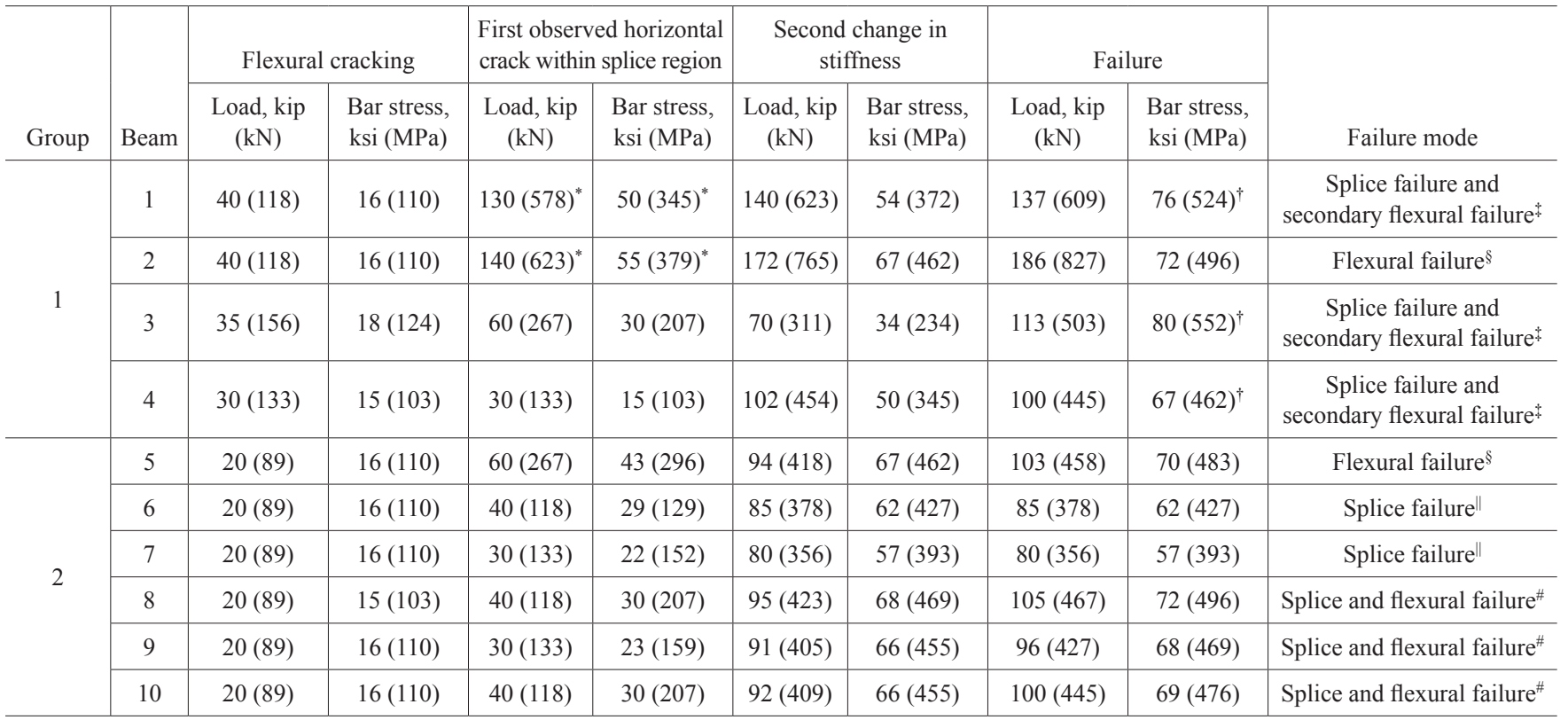

*Horizontal splitting cracks initiated on top surface.

${ }^{\dagger}$ Calculation based on tension reinforcement with two continuous bars only.

${ }^{\star}$ Splice failure before yielding of flexural reinforcement and secondary flexural failure after yielding of continuous bars.

${ }^{\S}$ Test was stopped after reinforcing steel yielded and crushing of concrete in compression zone was observed.

"Splice failure prior to yielding of flexural reinforcement.

\#Splice and flexural failure after yielding of flexural reinforcement.

\section{Group 1 beams}

All beams in Group 1 were subjected to Loading Protocol A. The two parameters in this group were splice length and the presence of reinforcement crossing the plane of the cold joint.

Beam 1-The load-deflection curve for Beam 1 (splice length of 33 in. [838 mm]) is presented in Fig. 5(a). The post-flexural cracking proportional limit was observed at a total load of $140 \mathrm{kip}(623 \mathrm{kN})$ and a total deflection of 1.14 in. (29 mm) (Fig. 5(a)). At this point, the calculated bar stress based on moment-curvature analysis was $54 \mathrm{ksi}$ (372 MPa) (Table 3 ). This value correlates very closely with the bar stress at failure of a $33 \mathrm{in} .(838 \mathrm{~mm})$ splice in monolithic concrete (53 ksi [365 MPa], as shown in Table 1) 
calculated using the splice strength expression proposed by ACI Committee 408 (2003). The splice strength expression proposed by ACI Committee 408 is used as a reference throughout this paper because it was calibrated to provide the best estimate of splice strength, unlike code equations calibrated to provide a safe estimate of splice strength. As the total displacement of the beam increased above 1.14 in. $(29 \mathrm{~mm})$, the total load suddenly dropped to approximately $133 \mathrm{kip}(592 \mathrm{kN})$, and then gradually increased again. The sudden reduction in load is attributed to the splice losing its load-carrying capacity, and the force carried by the spliced bar being transferred to the two continuous bars. Consistent with this failure hypothesis, a vertical splitting crack through the top cover (Fig. 6(a)) was first observed at a load of $130 \mathrm{kip}(578 \mathrm{kN})$ (corresponding to a calculated bar stress of $50 \mathrm{ksi}[345 \mathrm{MPa}$ ], assuming that all three bars carry equal force). Following failure of the splice, and assuming that past this point the tension force was carried entirely by the two continuous bars, a total load of $133 \mathrm{kip}(592 \mathrm{kN})$ corresponds to a calculated bar stress of $71 \mathrm{ksi}(489 \mathrm{MPa})$, which is equal to the measured yield stress of the steel. This shows that the two continuous bars would have yielded immediately following the failure of the splice. The gradual increase in the total load with increasing displacement observed at displacements greater than 1.14 in. $(29 \mathrm{~mm})$ is attributed to the effects of strain hardening in the continuous reinforcement. Loading continued and the test was stopped when crushing of the concrete in the compression face was observed in the region near the support. The load corresponding to the maximum deflection was $137 \mathrm{kip}(609 \mathrm{kN})$; the calculated bar stress at this load, based on the assumption that the two continuous bars carried all the demand due to bending, was $76 \mathrm{ksi}(521 \mathrm{MPa})$.

The two most significant characteristics of the observed mode of failure were that the bar stress at splice failure (54 ksi [372 MPa]) was very close to the nominal failure stress in monolithic concrete (53 ksi [365 MPa] based on the expression by ACI 408R), and that the major splitting cracks propagated through the top cover instead of the cold joint. Both of these characteristics indicate that the presence of eight side hoops across the plane of the crack on each side of the beam did provide an upper bound on restraint to the extent that the simulated crack played, at most, a small role on splice strength.

Beam 2-The cross-sectional dimensions and reinforcement for this beam were identical to those of Beam 1, with the exception that the splice length was 79 in. $(2007 \mathrm{~mm})$. The load-deflection curve for Beam 2 is shown in Fig. 5(b). The main difference with the load-deflection curve for Beam 1 (Fig. 5(a)) is that there was no drop in load after the post-flexural cracking proportional limit, which was observed at a total load of approximately $172 \mathrm{kip}(765 \mathrm{kN})$. If it is assumed that the post-flexural cracking proportional limit corresponded to yielding of the flexural reinforcement, with all three bars carrying the same force, the calculated bar stress based on moment-curvature analysis was $67 \mathrm{ksi}$ (462 MPa), which is slightly lower than the measured yield stress of the steel (71 ksi [489 MPa]). The $6 \%$ difference between calculated and yield stress could have been caused

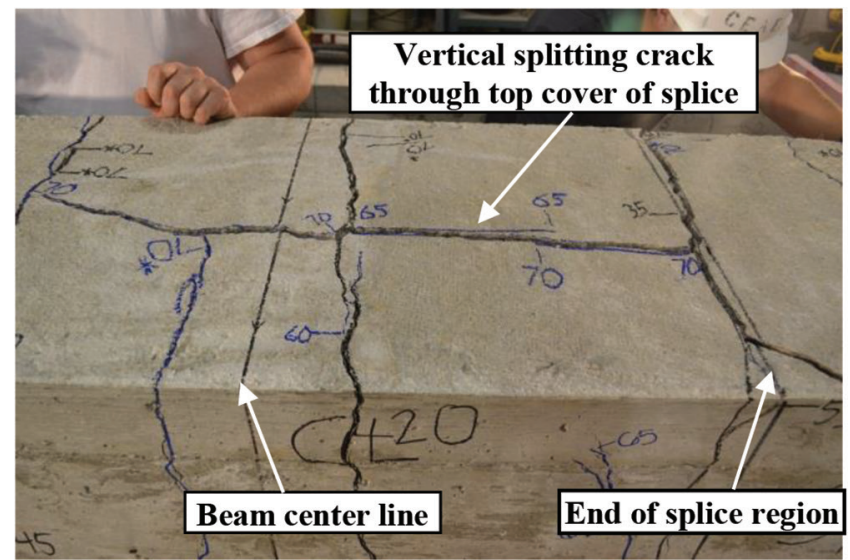

(a)

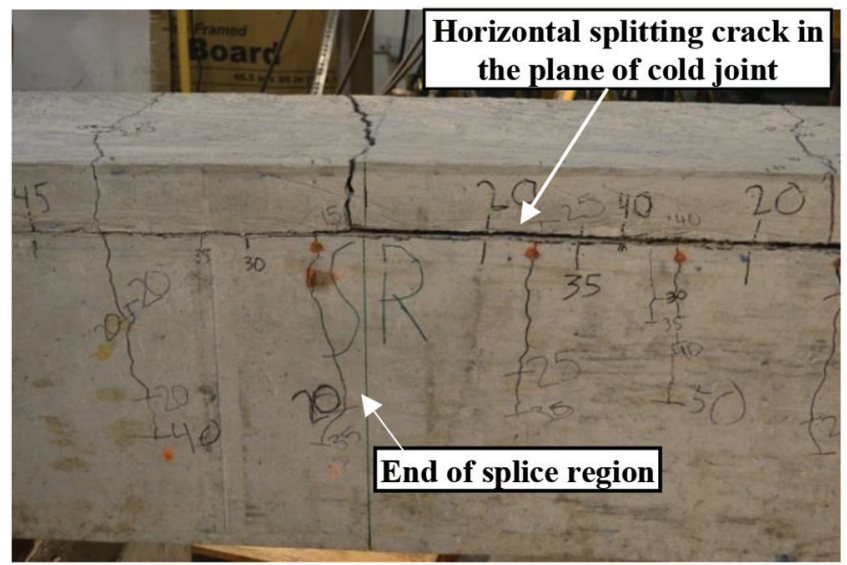

(b)

Fig. 6-(a) Vertical splitting crack through top concrete cover, as seen in Beams 1 and 2; and (b) horizontal splitting cracks through the cold joints, as seen in Beams 3 and 4.

by variations in the effective depth or yield stress of the reinforcement. It is also plausible that the spliced bar transferred some of its load to the two continuous bars, causing them to yield, although a reduction in stiffness would have been expected in the load-deflection relationship due to slip of the reinforcement. For reference, the bar stress at failure for a 79 in. $(2007 \mathrm{~mm})$ splice in monolithic concrete calculated using the expression proposed by ACI Committee 408 (2003) is $98 \mathrm{ksi}$ (676 MPa), which is significantly higher than the measured yield stress of the reinforcing bars used in this study.

After the post-flexural cracking proportional limit was reached, the total load continued to increase with increasing displacement as the reinforcing steel deformed into the strain hardening range. Loading was stopped when crushing of the concrete in the compression zone was observed in the constant moment region, at locations adjacent to the two supports. The measured load at flexural failure was $186 \mathrm{kip}$ $(827 \mathrm{kN})$, corresponding to a bar stress of $72 \mathrm{ksi}(496 \mathrm{MPa})$ in all three bars (Table 2). In light of the observed crack pattern and load-deflection measurements, it is the opinion of the authors that the splice in Beam 2 retained its load-carrying capacity up to the end of the test, when flexural failure occurred due to crushing of the concrete in the compression zone of the beam. 
The main difference in behavior between Beams 1 and 2 was that at deformations greater than the post-flexural cracking proportional limit, the load for Beam 2 remained above the load at the proportional limit. Splitting cracks similar to those commonly observed in tests of splices in monolithic concrete were observed mainly on the top surface of Beam 2, although the cracks were not as wide as in Beam 1. The crack patterns for Beams 1 and 2 showed that the side hoops were effective in keeping the cover in place, even after failure of the splice for Beam 1.

Beam 3-Beam 3 had nearly identical reinforcement and dimensions as Beam 1 (splice length of 33 in. [838 mm]), although Beam 3 contained no side hoops across the cold joint (Fig. 1(a) and Table 1). In Beams 3 and 4, the loading span was longer, and the cold joint extended further outside the splice region than in Beams 1 and 2, as described earlier. These changes were made to accommodate adjustments in the layout of the instrumentation.

The shape of the load-deflection curve for Beam 3 (Fig. 5(c)) was noticeably different from that of Beam 1. For Beam 3, there was a very gradual reduction in stiffness starting at a load of approximately 70 kip $(311 \mathrm{kN})$, and continuing up to a load of $102 \mathrm{kip}(454 \mathrm{kN})$, where the tangent stiffness became almost zero. Horizontal splitting cracks in the splice region were first observed at the cold joints at a load of approximately $60 \mathrm{kip}(267 \mathrm{kN})$. Assuming equal force in the three longitudinal bars, the calculated bar stresses corresponding to loads of 60 and 70 kip (267 and $311 \mathrm{kN}$ ) are 30 and $34 \mathrm{ksi}$ (207 and $234 \mathrm{MPa}$ ), respectively (Table 3). The bar stress corresponding to a load of $102 \mathrm{kip}$ $(454 \mathrm{kN})$, assuming that the splice had failed and the tensile force was carried entirely by the two continuous bars, is $71 \mathrm{ksi}(490 \mathrm{MPa})$, which is slightly above the measured yield stress for the reinforcing bars (67 ksi [462 MPa]). Based on the load readings, the shape of the load-deflection curve, and the observed crack pattern, it is concluded that failure of the splice initiated at a bar stress of $34 \mathrm{ksi}$ (324 MPa), which corresponds to $64 \%$ of the calculated capacity of the splice in monolithic concrete (53 ksi [365 MPa]), and that the force in the spliced bar was gradually transmitted to the two continuous bars until they reached yielding at a total load of $102 \mathrm{kip}(454 \mathrm{kN})$. As displacement increased beyond the yield point, the load-carrying capacity increased due to strain hardening of the reinforcement. The test was finally halted at a total load of $113 \mathrm{kip}(503 \mathrm{kN})$ due to the presence of large flexural cracks. The widest cracks in Beam 3 developed through the cold joint (Fig. 6(b)), which is indicative of splice failure through the plane of the cold joint. The location of the splitting cracks observed in Beam 3 was different from that observed in Beams 1 and 2, in which the splitting cracks propagated vertically through the top cover.

Beam 4-Beam 4 (splice length of 79 in. [2007 mm]) exhibited a sudden drop in load at the post-flexural cracking proportional limit, which is indicative of a sudden splice failure (Fig. 5(d)). The measured load at the proportional limit was $102 \mathrm{kip}(454 \mathrm{kN})$, corresponding to an average bar stress in the three bars of $50 \mathrm{ksi}(345 \mathrm{MPa})$ (Table 3), approximately $51 \%$ of the calculated failure stress of a similar splice in monolithic concrete (98 ksi [676 MPa], per
ACI 408R). After the peak load of $102 \mathrm{kip}(454 \mathrm{kN})$ was reached, the load dropped suddenly to approximately $87 \mathrm{kip}$ $(387 \mathrm{kN})$. It is concluded that the sudden failure of the splice led to redistribution of the tensile force, causing the two continuous bars to yield at a force of $87 \mathrm{kip}(387 \mathrm{kN})$. After yielding, the load gradually increased to approximately 100 kip (445 kN), which is attributed to strain hardening of the reinforcement, and remained nearly constant until the test was halted due to the presence of large flexural cracks. Similar to Beam 3, wide horizontal splitting cracks developed at the cold joint. The first horizontal splitting crack in the splice region was noted at a load of $30 \mathrm{kip}(133 \mathrm{kN})$, corresponding to a bar stress of $15 \mathrm{ksi}(103 \mathrm{MPa})$. The failure of the splice in Beam 4 was more brittle than in Beam 3 because the longer splice allowed more strain energy to be stored in the bar prior to failure, but otherwise the behavior of these two beams was similar. The reduction in strength due to the horizontal cracks was on the same order of magnitude (36\% for Beam 3 versus 49\% for Beam 4).

In summary, two bounding conditions were evaluated for the beams in Group 1. For the two beams without reinforcement crossing the plane of the crack (lower bound on restraint), splice strength was on the order of $50 \%$ lower than would be expected in monolithic concrete. If significant transverse reinforcement was provided across the plane of the crack for the concrete (upper bound on restraint), the presence of a preexisting crack in the plane of the reinforcing steel did not have a significant effect on splice strength, and the measured splice strengths were similar to those expected in monolithic concrete.

\section{Group 2 beams}

The specimens in this group contained two No. 11 (No. 36) bars with splices with lengths of 79 or 120 in. (2007 or $3048 \mathrm{~mm}$ ). The corresponding nominal lap splice strengths calculated using the ACI 408R expression for these splice lengths are 115 and $163 \mathrm{ksi}$ (793 and $1124 \mathrm{MPa}$ ) for concrete with a compressive strength of 5000 psi (34 MPa). These values indicate that the bars would be expected to yield prior to failure if embedded in monolithic concrete. All six beams in Group 2 contained one No. 3 (No. 10) side hoop (12 x 21 in. [305 x $533 \mathrm{~mm}]$ ) crossing the plane of the cold joint on each side of the beam, placed at the center of the specimen, outside the spliced bars (Fig. 2). The parameters in this group of tests were splice length, the presence of a cold joint, and loading protocol. Beam 5 was the only specimen in the study to be cast monolithically and had a splice length of 79 in. (2007 mm). Beams 6 and 7 were cast with a cold joint in the plane of reinforcing steel, but were otherwise identical to Beam 5. Beams $8,9$, and 10 had a splice length of 120 in. (3048 $\mathrm{mm})$ and cold joints in the plane of reinforcing steel. Beams 5, 6, and 8 were subjected to Loading Protocol A, while Beams 7, 9, and 10 were subjected to Loading Protocol B.

Beam 5-As stated earlier, calculations showed that the bars in this beam were expected to yield prior to failure of the splice. The load-deflection relationship for Beam 5, shown in Fig. 7(a), had a tri-linear shape. Horizontal splitting cracks were observed during the test, as shown in Fig. 8(a), although the dimensions of the cracks were not indicative 

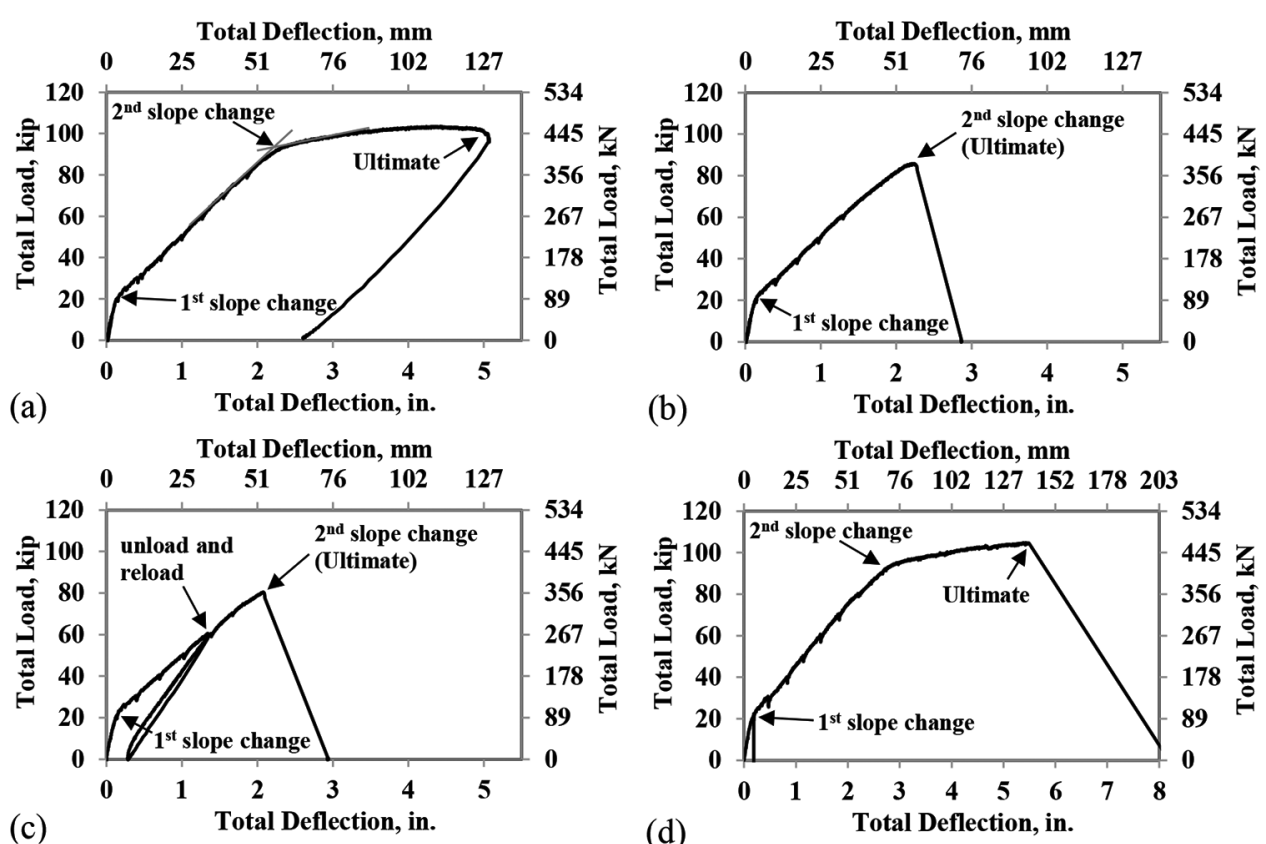

(b)

Total Deflection, mm

$\begin{array}{llllllllll}0 & 25 & 51 & 76 & 102 & 127 & 152 & 178 & 203\end{array}$

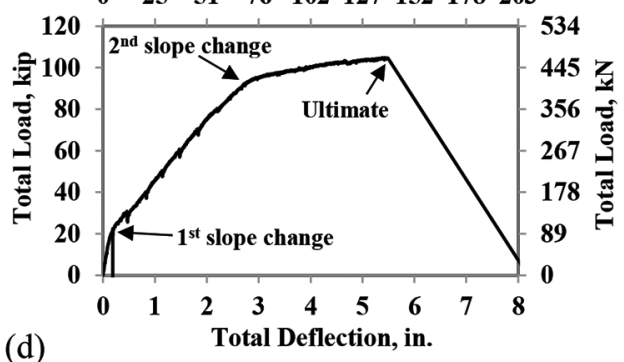

Fig. 7-Total load versus total deflection for: (a) Beam 5 (79 in. [2007 mm] splice length, cast monolithically Loading Protocol A); (b) Beam 6 (two side hoops, 79 in. [2007 mm] splice length, cold joint, and Loading Protocol A); (c) Beam 7 (two side hoops, $79 \mathrm{in.} \mathrm{[2007} \mathrm{mm]} \mathrm{splice} \mathrm{length,} \mathrm{cold} \mathrm{joint,} \mathrm{and} \mathrm{Loading} \mathrm{Protocol} \mathrm{B),} \mathrm{and} \mathrm{(d)} \mathrm{Beam} 8$ (two side hoops, $120 \mathrm{in}$. [3048 mm] splice length, cold joint, and Loading Protocol A).

of splice failure. The first horizontal splitting crack within the spliced region was observed below the post-flexural cracking proportional limit, at a total load of $60 \mathrm{kip}(267 \mathrm{kN})$, with a corresponding bar stress of $43 \mathrm{ksi}(296 \mathrm{MPa})$.

The post-flexural cracking proportional limit was observed at a total load of $94 \mathrm{kip}(418 \mathrm{kN})$, which corresponded to a calculated bar stress of $67 \mathrm{ksi}(462 \mathrm{MPa})$, equal to the measured yield stress of the reinforcing bars used in Group 2. These measurements indicate that the post-flexural cracking proportional limit was associated with yielding of the flexural reinforcement. As displacement increased beyond the proportional limit, the load continued to increase. The positive slope of the load-deflection relationship at displacements greater than the post-flexural cracking proportional limit is attributed to strain hardening of the reinforcement. Loading continued until a flexural failure occurred due to crushing of the concrete in the compression zone (Fig. 8(b)) near the supports. The total load at failure was $103 \mathrm{kip}(458 \mathrm{kN})$, corresponding to a calculated bar stress of $70 \mathrm{ksi}(483 \mathrm{MPa})$.

Beams 6 and 7-These two beams were nearly identical to Beam 5, with the only difference being that Beams 6 and 7 had cold joints in the plane of reinforcing steel. Beam 6 was subjected to Loading Protocol A, while Beam 7 was subjected to Loading Protocol B. The maximum load during the initial cycle for Beam 7 was 60 kip $(267 \mathrm{kN})$, corresponding to a bar stress of $43 \mathrm{ksi}(296 \mathrm{MPa})$, and the maximum width of horizontal cracks in the plane of cold joint prior to unloading was 20 mils $(0.51 \mathrm{~mm})$.

The load-deflection curves for Beams 6 and 7 are shown in Fig. 7(b) and (c). The first horizontal splitting cracks within the splice region of Beams 6 and 7 were observed at total loads of 40 and $30 \mathrm{kip}$ (178 and $133 \mathrm{kN}$ ), respectively, corresponding to inferred bars stresses of 29 and $22 \mathrm{ksi}$ (200 and

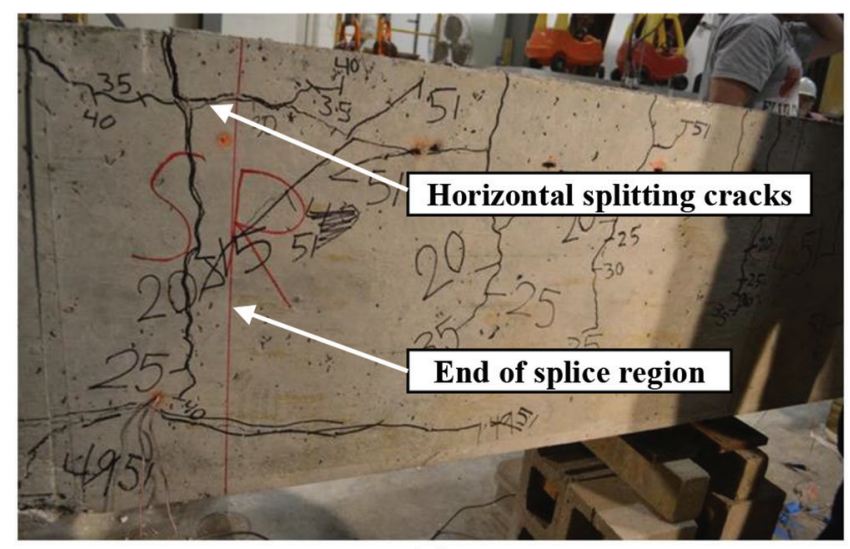

(a)

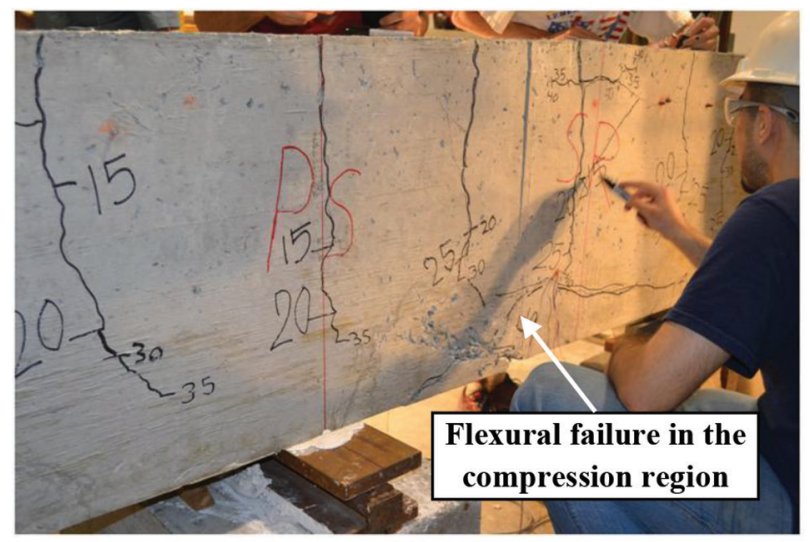

(b)

Fig. 8-Crack pattern in Beam 5: (a) horizontal splitting cracks at end of splice region; and (b) flexural failure in compression region. Numbers indicate maximum average end load when cracks were marked. 


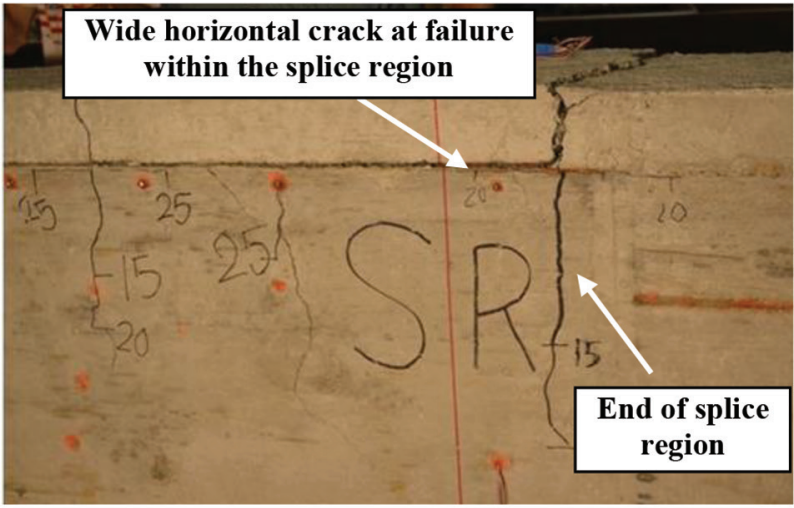

(a)

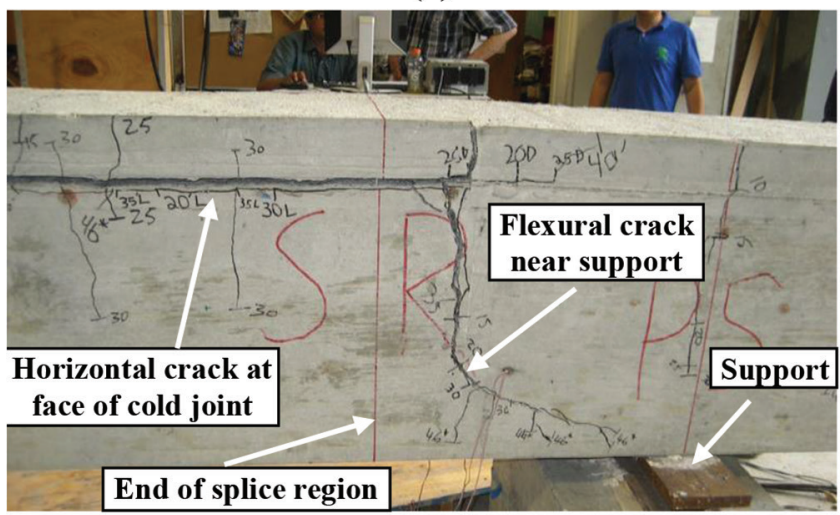

(b)

Fig. 9-Failure mode for: (a) Beam 6 with wide horizontal crack along the cold joint; and (b) Beam 8 with horizontal crack along plane of reinforcing steel and flexural cracks near the support.

$152 \mathrm{MPa}$ ). In both instances, the cracks initiated at the cold joints.

Beams 6 and 7 failed due to sudden splitting of the concrete along the cold joint in the splice region (Fig. 9(a)). The loads at failure for Beams 6 and 7 were 85 and 80 kip (378 and $552 \mathrm{kN}$ ), respectively, which correspond to calculated bars stresses of 62 and $57 \mathrm{ksi}$ (427 and $393 \mathrm{MPa}$ ), both below the measured yield stress of $67 \mathrm{ksi}$ (462 MPa). Based on the shape of the load-deflection curves and the observed behavior during the tests, it is concluded that Beams 6 and 7 had splice failures. This mode of failure was confirmed by direct observation of bar slip at the ends of the lap splice, after the cover was removed for final inspection (Fig. 10).

A comparison of the load-deflection curves and crack patterns of Beams 6 and 7 shows that the horizontal cracks that formed in Beam 7 during the first loading cycle did not have a significant effect on the behavior at failure. It is noted though that these $20 \mathrm{mil}(0.51 \mathrm{~mm})$ wide cracks were relatively short, with a length of approximately 12 in. (305 mm).

In summary, the effect of preexisting cracks on nominal splice strength was found to be significant for beams of Group 2 with a splice length of 79 in. (2007 mm) (Beams 5, 6 , and 7). Splices in Beam 5, which was cast monolithically and failed in flexure, had no indication of failure during the test. This was in direct contrast with the behavior of Beams 6 and 7, which had a cold joint in the plane of the

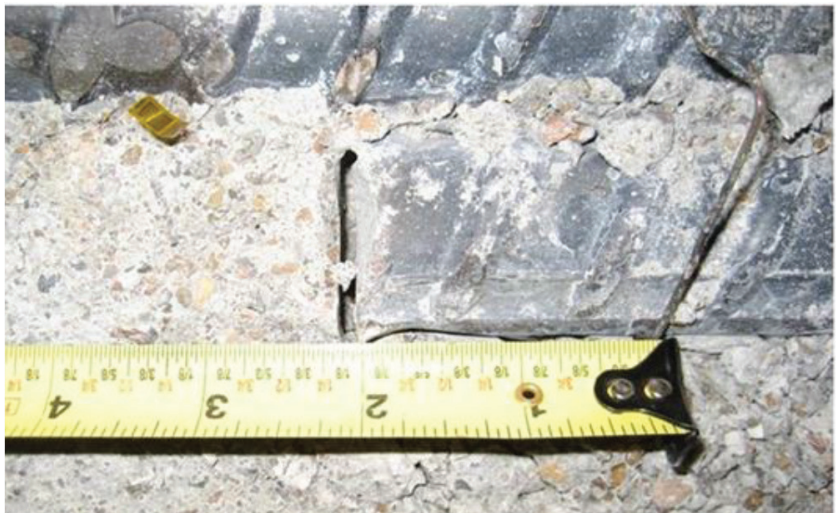

(a)

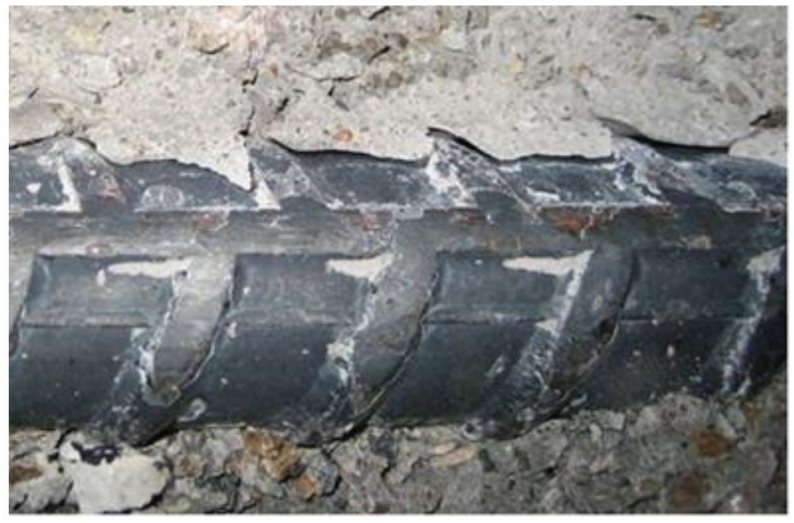

(b)

Fig. 10-Splice condition during post-test inspection of Beam 6: (a) bar slip; and (b) separated concrete around spliced bar.

reinforcement. In these two beams, a sudden splice failure was observed prior to yielding of the bars, at stresses of 62 and $57 \mathrm{ksi}$ (427 and $393 \mathrm{MPa}$ ), respectively. These bar stresses were on the order of $50 \%$ of the nominal splice strength calculated with the ACI 408R expression (115 ksi [793 MPa]), although it is important to recognize that the failure stresses were $93 \%$ and $85 \%$ of the yield stress of the longitudinal bars, and approximately equal to the nominal yield stress of the reinforcement. The behavior of Beams 6 and 7, which had two side hoops and a 79 in. (2006 mm) splice length, closely resembled that of Beam 4, which had the same splice length but no side hoops, and failed at a bar stress $49 \%$ lower than that calculated with the splice strength equation in ACI 408R.

Beams 8, 9, and 10-Beam 8 was subjected to Loading Protocol A, while Beams 9 and 10 were subjected to Loading Protocol B. The peak load in the initial cycle of Beams 9 and 10 was $40 \mathrm{kip}(178 \mathrm{kN})$ in both cases, corresponding to a bar stress of $30 \mathrm{ksi}(207 \mathrm{MPa})$. The maximum crack widths measured at the peak of the first cycle were 35 and 30 mils (0.90 and $0.76 \mathrm{~mm})$, respectively.

The load-deflection relationships for Beams 8, 9, and 10 are shown in Fig. 7(d), 11(a), and 11(b), respectively. All three beams exhibited similar behavior during loading. The first horizontal splitting cracks within the splice region were observed at total loads of 40, 30, and 40 kip (178, 133, and $178 \mathrm{kN}$ ) for Beams 8, 9, and 10, respectively. The corre- 


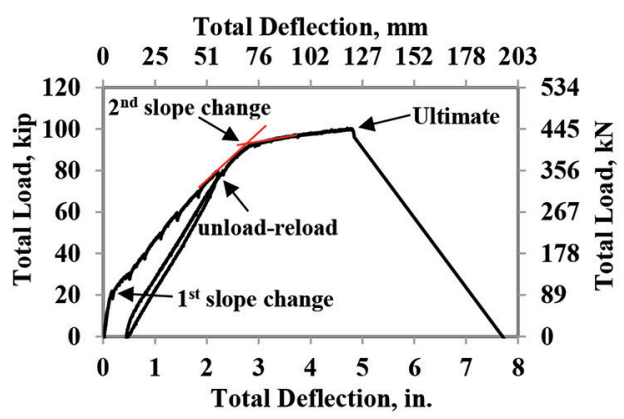

(a)

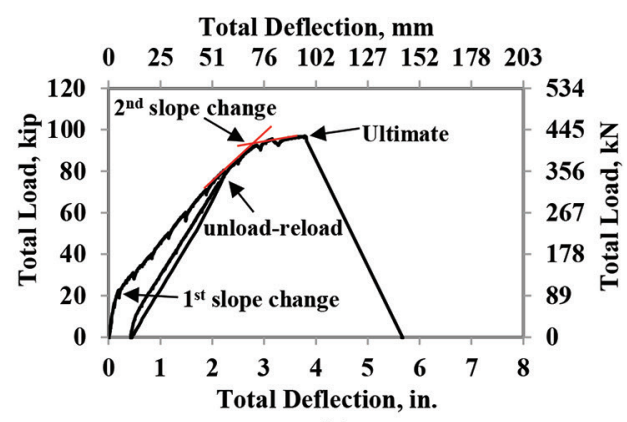

(b)

Fig. 11-Total load versus total deflection for: (a) Beam 9 (two side hoops, $120 \mathrm{in}$. [3048 mm] splice length, cold joint, and Loading Protocol B); and (b) Beam 10 (two side hoops, 120 in. [3048 mm] splice length, cold joint, and Loading Protocol B).

sponding bars stresses were 30, 23, and $30 \mathrm{ksi}(207,159$, and $207 \mathrm{MPa}$ ), respectively. The horizontal cracks initiated in the cold joints for all three cases. Similar to Beam 7, horizontal cracks in the cold joints of Beams 9 and 10 that initiated during the first loading cycle did not have a significant effect on the behavior at failure.

The post-flexural cracking proportional limit of the three load-deflection relationships was observed at total loads of 95, 91, and $92 \mathrm{kip}(423,405$, and $409 \mathrm{kN})$ for Beams 8, 9 and 10 , respectively. Based on moment-curvature analyses, the calculated bar stresses associated with those loads were 68, 66, and $66 \mathrm{ksi}(469,323$, and $323 \mathrm{MPa})$, respectively, which are nearly equal to the yield stress of the reinforcement (67 ksi [462 MPa]). As deformation increased beyond the post-flexural cracking proportional limit, the slope of the load-deflection relationship remained positive, which is attributed to strain hardening of the reinforcement. All three beams failed in a sudden manner with wide horizontal cracks in the plane of the cold joint and flexural cracks near the support (the latter shown in Fig. 9(b)). The loads at failure for Beams 8, 9, and 10 were 105, 96, and 100 kip $(467,427$, and $445 \mathrm{kN}$ ), corresponding to bar stresses of 72,68 , and $69 \mathrm{ksi}(496,469$, and $476 \mathrm{MPa})$, respectively. Based on these measurements and the shape of the load-deflection relationships, it is concluded that in all three cases the splices failed after yielding of the bars. Bar slip was observed in the three beams after removal of the concrete cover for final inspection.

The test results show that for beams with a splice length of 120 in. $(3048 \mathrm{~mm})$ and two side hoops crossing the plane of the crack, the presence of preexisting cracks in the plane of the reinforcement did not cause the splice strength to drop below the yield stress of the reinforcement. Based on the results from Beams 1 through 7, it is concluded that the two side hoops provided in Beams 8 through 10 had only a minor effect on splice strength, and that the same type of behavior would be expected for beams with 120 in. (3048 mm) splices without any transverse reinforcement crossing the plane of the crack.

\section{SUMMARY AND CONCLUSIONS}

The effect of preexisting cracks oriented in the plane of the reinforcing steel on the strength of No. 11 (No. 36) bar lap splices was investigated. Cold joints were introduced at the midheight of the reinforcing steel to simulate the preexisting cracks. Some of the beams were loaded in two stages to induce horizontal cracks at the face of the cold joint prior to being loaded monotonically to failure. Two different configurations of side hoops were used to simulate restraint provided by concrete adjacent to the splices.

The following conclusions are based on the test results and analysis presented in this paper.

1. The presence of the cold joints provided a significant reduction in tensile capacity in the plane of the splices as evidenced by a reduction in the modulus of rupture on the order of $60 \%$ or more.

2. For splices with a significant constraining force (provided by eight side hoops on each side of the splice region), the effect of preexisting cracks in the plane of the reinforcement on splice strength was negligible for the range of splice lengths evaluated.

3. For splices with a small constraining force (provided by one side hoop on each side of the splice region), or without any constraining force, the presence of preexisting cracks in the plane of the reinforcement resulted in a large reduction in lap splice strength. For the configurations evaluated in this paper, the reduction was on the order of $50 \%$. Even though this reduction was very significant in terms of percentage, its practical effect on the bar stress at failure varied with the length of the splice due to the fact splice strength increases with splice length. Splices with a length of $120 \mathrm{in} .(3048 \mathrm{~mm})$ in beams with preexisting cracks were sufficiently long to preclude failure of the splice prior to yielding of the reinforcement, even when the effect of the reinforcement crossing the plane of the preexisting crack was negligible. The main effect of preexisting cracks in beams with 120 in. (3048 mm) long splices was to cause the failure of the splices after yielding of the reinforcement, at a lower deformation than would be achievable if the splices were embedded in monolithic concrete. For beams with 79 in. $(2007 \mathrm{~mm})$ long splices, the reduction in strength led to splice failures prior to yielding of the reinforcement, although at stresses approximately equaled the nominal yield stress of the bars (60 ksi [414 MPa]). For bars with 33 in. $(838 \mathrm{~mm})$ splices and without any reinforcement crossing the plane of the preexisting cracks, splice failures took place well below the yield stress; although it is important to note that in monolithic concrete, the splices would be expected to fail prior to yielding of the reinforcement as well, albeit at a significantly larger bar stress. 


\section{AUTHOR BIOS}

ACI member Jiqiu Yuan is a Project Manager for the Building Seismic Safety Council and Multihazard Mitigation Council at the National Institute of Building Sciences. He received his BS in material science and engineering from Tongji University, Shanghai, China; his MS in material science and engineering from China Building Materials Academy, Beijing, China; and his PhD in civil engineering from the University of Kansas, Lawrence, KS. He is a member of ACI Committee 239, Ultra-High Performance Concrete; ACI Subcommittee 228-B, Visual Inspection; and Joint ACI-ASCE Committee 408, Bond and Development of Steel Reinforcement.

ACI member Matthew O'Reilly is an Assistant Professor in the Department of Civil, Environmental and Architectural Engineering at the University of Kansas. He received his BS from the University of Rochester, Rochester, NY, and MS and PhD from the University of Kansas. He is a member of ACI Committee 222, Corrosion of Metals in Concrete.

Adolfo Matamoros, FACI, is a Professor and Peter T. Flawn Distinguished Chair at the University of Texas at San Antonio, San Antonio, TX. He received his licentiate degree from the University of Costa Rica, San Pedro, Costa Rica, and his MS and PhD from the University of Illinois at UrbanaChampaign, Champaign, IL. He is a member of ACI Committees 369, Seismic Repair and Rehabilitation, and 374, Performance-Based Seismic Design of Concrete Buildings, and Joint ACI-ASCE Committees 335, Composite and Hybrid Structures; 408, Bond and Development of Steel Reinforcement; and 445, Shear and Torsion. His research interests include earthquake engineering, shear, and bond in reinforced concrete members.

ACI Honorary Member David Darwin is the Deane E. Ackers Distinguished Professor and Chair of the Department of Civil, Environmental and Architectural Engineering at the University of Kansas and a Past President of ACI. He is a member of ACI Committees 222, Corrosion of Metals in Concrete; and 224, Cracking; ACI Subcommittee 318-B, Anchorage and Reinforcement; and Joint ACI-ASCE Committees 408, Bond and Development of Steel Reinforcement; 445, Shear and Tosion; and 446, Fracture Mechanics of Concrete.

\section{REFERENCES}

ACI Committee 408, 2003, "Bond and Development of Straight Reinforcing Bars in Tension (ACI 408R-03)," American Concrete Institute, Farmington Hills, MI, 49 pp.
ACI Committee 408, 2009, "Guide for Lap Splice and Development Length of High Relative Rib Area Reinforcing Bars in Tension (ACI 408.3R-09) and Commentary," American Concrete Institute, Farmington Hills, MI, $12 \mathrm{pp}$.

ASTM A615/A615M-13, 2013, "Standard Specification for Deformed and Plain Carbon-Steel Bars for Concrete Reinforcement," ASTM International, West Conshohocken, PA, 7 pp.

ASTM C78/C78M-10, 2010, "Standard Test Method for Flexural Strength of Concrete (Using Simple Beam with Third-Point Loading),' ASTM International, West Conshohocken, PA, 4 pp.

Darwin, D.; Dolan, C. W.; and Nilson, A. H., 2016, Design of Concrete Structures, 15th edition, McGraw-Hill, New York, 786 pp.

Darwin, D.; Tholen, M. L.; Idun, E. K.; and Zuo, J., 1996, "Splice Strength of High Relative Rib Area Reinforcing Bars," ACI Structural Journal, V. 93, No. 1, Jan.-Feb., pp. 95-107.

Eligehausen, R., 1979, "Bond in Tensile Lapped Splices of Ribbed Bars with Straight Anchorages," Publication 301, German Institute for Reinforced Concrete, Berlin, Germany, 118 pp. (in German)

Hognestad, E., 1951, "A Study of Combined Bending and Axial Load in Reinforced Concrete Members," University of Illinois Engineering Experimental Station Bulletin Series, No. 399, University of Illinois, Urbana, IL, 128 pp.

NRC, 2013, "Shield Building Concrete Subsurface Laminar Cracking Caused by Moisture Intrusion and Freezing," NRC Information Notice 2013-04, Nuclear Regulatory Commission, Washington, DC, 5 pp.

Orangun, C. O.; Jirsa, J. O.; and Breen, J. E., 1977, "Reevaluation of Test Data on Development Length and Splices," ACI Journal Proceedings, V. 74, No. 3, Mar., pp. 114-122.

Tepfers, R., 1973, "A Theory of Bond Applied to Overlapping Tensile Reinforcement Splices for Deformed Bars," Publication 73:2, Division of Concrete Structures, Chalmers University of Technology, Goteborg, Sweden, $328 \mathrm{pp}$.

Untrauer, R. E., 1965, discussion of "Development Length for Large High Strength Reinforcing Bars," ACI Journal Proceedings, V. 62, No. 9 , Sept., pp. 1153-1154.

Yuan, J.; O'Reilly, M.; Matamoros, A.; and Darwin, D., 2012, "Effect of Simulated Cracks on Lap Splice Strength of Reinforcing Bars," SL Report 12-2, University of Kansas Center for Research, Lawrence, KS.

Zuo, J., and Darwin, D., 2000, "Splice Strength of Conventional and High Relative Rib Area Bars in Normal and High-Strength Concrete," ACI Structural Journal, V. 97, No. 4, July-Aug., pp. 630-641. 